\title{
Study on Sustainable Development of Forest Products Industry Based on Circular Economy
}

\author{
Weitao Xu' ${ }^{1}$, Feng $\mathrm{Shi}^{2}$, An Mao ${ }^{3, *}$, Yifu Yuan ${ }^{3, *}$ \\ ${ }^{1}$ Planning and Design Institute of Forest Products Industry of National Forestry and Grassland Administration, Beijing, China \\ ${ }^{2}$ China National Forest Products Industry Association, Beijing, China \\ ${ }^{3}$ College of Forestry, Shandong Agricultural University, Taian, China
}

Email address:

mjgbw_001@163.com (Weitao Xu),cnfpia001@163.com (Feng Shi),dannymaoan@126.com (An Mao), yuaneco@sdau.edu.cn (Yifu Yuan)

*Corresponding author

\section{To cite this article:}

Weitao Xu, Feng Shi, An Mao, Yifu Yuan. Study on Sustainable Development of Forest Products Industry Based on Circular Economy. American Journal of Agriculture and Forestry. Vol. 8, No. 4, 2020, pp. 126-130. doi: 10.11648/j.ajaf.20200804.15

Received: June 21, 2020; Accepted: July 4, 2020; Published: July 23, 2020

\begin{abstract}
China is a country with insufficient forest resources, small forest area, small number of resources and unbalanced regional distribution. China is also a typical big country of forest products production and consumption, and also the largest forest products processing and production base, and the most important forest products processing and export country in the world. The development of forest product industry needs to consume a lot of forest resources, and the traditional industry mainly depends on the supply of natural forest. Modern forest product industry is an industry that makes full use of advanced science and technology, based on the principle of circular economy, efficiently uses and recycles forest resources to meet the increasing demand of human beings for forest products. The sustainable development of forest product industry in China needs circular economy. Circular economy is the fundamental way to solve the contradiction between economic development and ecological environment. This paper introduced the basic concept of circular economy and the general situation of the development of modern forest product industry. The necessity of the development of circular economy and the realization of sustainable development of forest product industry were discussed. Suggestions were also put forward for the realization of circular economy in forest product industry.
\end{abstract}

Keywords: Circular Economy, Forest Product Industry, Sustainable Development, Environmental Protection

\section{Introduction}

China is a country with insufficient forest resources, small forest area, small number of resources and unbalanced regional distribution. Statistics in 1990 showed that (Table 1): the world's forest area was about 4.019 billion hectares, and the per capita area was about 0.8 hectares, while China's forest area was 124.6 million hectares, and the per capita area was only 0.107 hectares, accounting for only $13.4 \%$ of the world's per capita forest area; the world's forest coverage rate was $31 \%$, and China's forest coverage rate was only $12.98 \%$; the world's forest storage volume was about 310 billion cubic meters, and the per capita storage volume was about 72 cubic meters Square meters, China's forest stock was 9.14 billion cubic meters, per capita stock was only 8 cubic meters. In recent years, China's forest resources have continued to grow.
The results of the eighth Forest Resources Inventory (2009-2013) showed that the national forest area was 208 million hectares, the forest coverage rate was $21.63 \%$, the total volume of standing trees was 16.433 billion cubic meters, and the forest volume was 15.137 billion cubic meters. Among them, the natural forest area was 122 million hectares, with a volume of 12.296 billion cubic meters; the artificial forest area was 69 million hectares, with a volume of 2.483 billion cubic meters.

Although China's forest resources have shown a good trend of continuous increase in quantity, steady improvement in quality and continuous enhancement in efficiency, with the profound changes in the international situation, the form of national security has changed fundamentally, and forest resources have changed from meeting people's daily life needs to an environmental ecological demand [1-3]. Forest resources have attracted the attention of all countries in the 
world. Wood problem has gradually evolved into one of the national strategic issues, whose essence is the issue of wood security $[4,5]$. China is a typical big country of forest products production and consumption, and also the largest forest products processing and production base, and the most important forest products processing and export country in the world. The development of forest product industry needs to consume a lot of forest resources, and the traditional industry mainly depends on the supply of natural forest. In August 1998, due to the nationwide flooding, the central government made a decision to ban and restrict the cutting of natural forests in the upper reaches of the Yangtze River and the middle and upper reaches of the Yellow River. In 2000, the first phase of the natural forest protection project was officially implemented, and by 2020 , the second phase of the natural forest protection project was completed, which lasted for 20 years. Due to the national protection of forest resources, although the economic demand for wood is increasing year by year, and the gap is growing day by day, however, the gap is not made up by increasing the cutting amount of natural forest, but by cultivating artificial forest and expanding the import of wood to meet the growing domestic demand. In recent years, China's timber import volume has increased significantly. In 2018, China imported 111944000 cubic meters of timber ( $\log +$ sawn timber), with an import volume of 21.09 billion US dollars, up 3.2\% and $5.6 \%$ respectively year on year. In 2020, China's wood demand is expected to reach 800 million cubic meters, and the gap will exceed 200 million cubic meters.

Table 1. Comparison of forest resources between China and the world.

\begin{tabular}{llll}
\hline \multirow{2}{*}{ Index of Forest Resources } & \multicolumn{2}{l}{ Data Published in 1990 } & \multicolumn{2}{l}{ Results of the Eighth Forest Resources Inventory } \\
\cline { 2 - 4 } & China & World & China \\
\hline Forest area (100 million ha) & 1.246 & 40.19 & 2.08 \\
Per capita forest area (ha) & 0.107 & 0.8 & - \\
Forest coverage (\%) & 12.98 & 31 & 20.36 \\
Forest volume (100 million cubic meters) & 91.4 & 3100 & 151.37 \\
Per capita forest volume (100 million cubic meters) & 8 & 72 & - \\
\hline
\end{tabular}

With the rapid development of China's economy and the continuous improvement of people's living standards, the demand for wood will only increase year by year, and the growing demand gap cannot completely rely on wood imports. China imports a large amount of timber from Africa and Southeast Asia every year. Since 2019, some countries in these regions have successively issued decrees to restrict or prohibit the export of logs. Therefore, the fundamental way to solve the wood demand gap is not to rely on imports, but to increase the construction of domestic fast-growing plantation and increase the supply of plantation resources, so as to meet the domestic demand for wood stably and sustainably and solve the problem of wood safety from the root. However, in addition to this "open source" approach, we also need to do a good job in "cutting costs", that is, to strengthen wood conservation and utilization and achieve sustainable development of the forest product industry [6].

\section{General Situation of Forest Product Industry in China}

\subsection{Modern Forest Product Industry}

Modern forest product industry is an industry that makes full use of advanced science and technology, based on the principle of circular economy, efficiently uses and recycles forest resources to meet the increasing demand of human beings for forest products [7]. In the process of wood processing, wood or non-wood natural fiber is transformed into various products by mechanical, physical or chemical methods to meet the needs of people's production and life. Different from the traditional forest product industry, the modern forest product industry needs efficient utilization and recycling of wood to increase the added value of products and reduce the loss of wood in the process of processing. Forest product industry and forest chemical industry are both follow-up industries of forest resource cutting, which are important departments of comprehensive utilization of wood resources and leading industries of the whole forestry industry.

In recent years, with the rapid development of China's forest product industry, wood-based panels, furniture, papermaking and architectural decoration have a huge demand for wood, of which about $2 / 3$ of the industrial wood is consumed in the paper and pulping industry. In 2018, China's paper-making material volume has exceeded 400 million cubic meters, the output of wood-based panels is close to 300 million cubic meters, and the output value of furniture has reached 225 billion yuan [8]. Facing the huge demand of industrial timber, in recent years, China's timber gap is more than 100 million cubic meters every year. Due to the less and less available forest resources, we have to import timber and products from abroad every year. Its import volume has exceeded steel, ranking second only to oil.

\subsection{Characteristics and Utilization of Wood}

Wood is the only renewable material among the four traditional materials. It is a kind of biomass material with many excellent characteristics, and also an important industrial raw material. Wood has the advantages of light weight, high ratio of strength to weight, good elasticity, impact resistance, rich and beautiful texture and tone, and easy processing. The forest product industry plays an important role in the national economy, covering the following areas: wood machining, wood composite material manufacturing, wood functional improvement, wood gluing, pulp and paper making, etc. Its products are mainly used in 
construction and decoration industry, furniture manufacturing industry and paper industry. Wood not only can be obtained from natural forest, but also can be obtained from artificial forest by using its renewable characteristics. This is the biggest characteristic and advantage of wood compared with other traditional materials. The cultivation of fast-growing plantation for timber can effectively improve the situation of forest resources shortage and greatly alleviate the shortage of timber consumption.

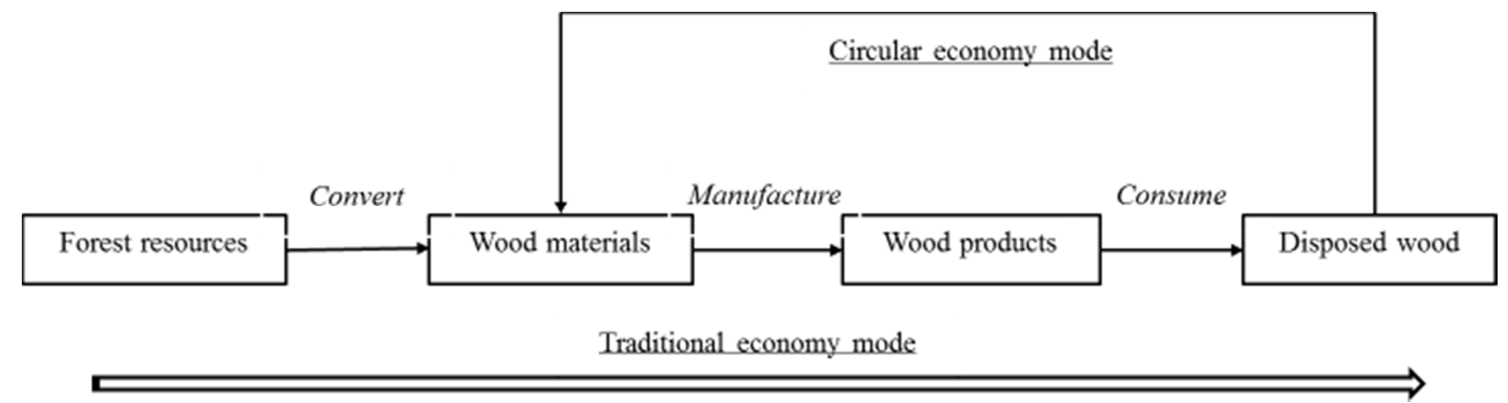

Figure 1. Circular economy mode.

\section{Circular Economy Overview}

The traditional economic model is "resources products pollution discharge", which is an open-loop, one-way flow economic model (Figure 1). The utilization of resources is extensive and one-time, which is the main factor causing the contradiction between economic development and ecological environment. Circular economy, also known as "resource circular economy", is the abbreviation of material closed circular flow economy. It is an economic development mode characterized by resource conservation and recycling and harmonious with the environment. It emphasizes the feedback process of organizing economic activities into a "resource product regenerating resource" (Figure 1). It is characterized by the "3R" principle of reduction, reuse and recycle [9]. In the whole process of production and consumption, there is no or only a small amount of waste. All materials and energy can be reasonably and sustainably used in this continuous economic cycle, so as to reduce the impact of economic activities on the natural environment to the smallest extent possible. Therefore, we can fundamentally solve the contradiction between the current economic development and the natural environment $[10,11]$. At the world "thinker forum" in 2005, the "3R" principle was further expanded to the "5R" principle, which added the principles of rethink and repair on the basis of reduction, reuse and recycle, further enriching the concept of circular economy [12].

The fundamental purpose of circular economy is to reduce the resource input as much as possible in the economic process, and systematically avoid and reduce waste, recycle waste and reduce the final treatment capacity of waste. Its main contents include the following three aspects $[13,14]$ :

1) The development of new products runs through the concept of "reduction, reuse and recycling". Product development specifically includes all aspects of product design, including creativity, conception, pollution-free raw materials and processes, pollution-free selection, product manufacturing, use, waste recycling, recycling and other aspects, that is, the evaluation of the whole life cycle of the product. While considering the basic functional attributes of the product, the negative effects of the product and process on the environment should be avoided or reduced Face effects.

2) The concept of "reduction, reuse and recycling" runs through the whole life cycle of material resources development and utilization. Among them, "reduction" requires less resources and energy input to achieve the established production and consumption purposes; "reuse" requires that the products produced can be reused; "recycling" requires that the products can be restored to usable resources after consumption. Through the implementation of the principle of "reduction, reuse and recycling", the impact on the environment will be minimized in the process of resource utilization, so as to achieve the goal of circular economy.

3) The reuse and recycling of ecological environment resources. That is, the reproduction and reuse of renewable resources in the environment, the restoration, reuse and recycling of space and environmental resources.

\section{Circular Economy and Sustainable Development of Forest Product Industry}

Resources and environment are the main factors that restrict the development of China's forest product industry. The contradiction between effective forest supply and increasing economic demand is still prominent. China's wood dependence on foreign countries is close to $50 \%$, and the wood security situation is grim; the available area of the existing timber forest is only $13 \%$, and the available volume is only $23 \%$, with less available resources, less large-diameter timber and precious timber species, and the structural contradiction between the supply and demand of timber is very prominent. At the same time, the fragile function of forest ecosystem has not been fundamentally changed, and the shortage of ecological products is still a prominent problem restricting the sustainable development of China. The concept of circular economy comes from people's thinking about the 
energy crisis and resource security in recent years, and then forms the strategic idea of circular economy which integrates clean production, comprehensive utilization of resources, ecological design and sustainable consumption into a system. The circular economy mode is applied to the forest product industry to recycle the wood products, so that the wood waste becomes a part of the circular economy. It is the inevitable choice for the sustainable development of the forest product industry to solve the problem of resource shortage by using the waste. In October 2019, the State Forestry and grassland Administration issued the revised industry standard "Specification for recycling of waste wood" (LY/T1822-2019) [15], which stipulates the definition, basic principles, classification, recycling, storage and transportation, recycling and the safety and environmental protection requirements for recycling of waste wood. The implementation of the new standard will better promote the forest product industry Sustainable development.

\subsection{The Necessity of Developing Circular Economy in Forest Product Industry}

1) Alleviate the shortage of wood resources. In the process of wood processing, a variety of leftover materials and waste wood materials are produced, a large part of which can be reused. At present, the utilization rate of wood processing in China is only about $60 \%$, which is much lower than that in developed countries. Therefore, if the waste wood materials can be recycled, the utilization rate of wood in China can be greatly improved, and the shortage of wood resources can be effectively alleviated.

2) Improve the ecological environment. Waste water and waste gas are discharged from wood processing, and the energy utilization rate is low. The discharged waste water and waste gas seriously pollute the urban environment. Most of the solid wastes are treated by landfill and incineration, which has a great negative impact on the groundwater and soil. In addition, the harmful gases (formaldehyde, benzene series, etc.) in the wood plate may have a great impact on human health. The development of circular economy can effectively utilize the waste, significantly reduce the emission of pollutants and improve the ecological environment.

3) Save energy and improve economic efficiency. The energy consumption of wood processing process is large, the recycling of resources can save a lot of energy, the effect is more obvious than the progress of technology and equipment. The recycling of wood resources can reduce the cultivation of forest areas, shorten the production process, reduce the capital investment and production costs. The price of the recycled waste wood is low, which can reduce the cost of raw materials, save a lot of money, and significantly improve the economic efficiency.

\subsection{Measures and Suggestions for the Development of Circular Economy in Forest Product Industry}

To develop sustainable forest product industry, we need to make rational, economical and comprehensive use of wood, improve the level of comprehensive utilization of wood, achieve efficient utilization and realize sustainable industrial cycle. Specifically, the following aspects need to be achieved:

1) The State shall formulate relevant policies and regulations, establish a circular economy development system, and ensure the smooth implementation of circular economy. The policy should reflect the core concept of "reduction, reuse and recycling" of circular economy, i.e. waste emission reduction, resource recycling and energy consumption reduction; the obligation and responsibility of waste recycling in the production process should be defined in the regulations, so as to achieve the purpose of economic cycle.

2) Vigorously promote the concept of circular economy, widely publicize through various channels, cultivate the public awareness of environmental protection, form a kind of social public knowledge, enable the public to consciously follow the concept of circular economy in life and production, and take environmental protection, energy conservation and emission reduction as a code of conduct.

3) We will increase support for scientific and technological innovation, increase investment in research and development, pool multi-disciplinary and multi field forces, develop new technologies, processes and products that can improve wood processing and utilization efficiency, extend wood use time, effectively utilize non wood resources, reduce waste emissions, and save energy, solve common problems and bottlenecks that hinder the realization of circular economy, and promote new materials Transformation of achievements in materials, new energy, waste recycling and other fields.

\section{Conclusion}

Circular economy is the fundamental way to solve the contradiction between economic development and ecological environment. The sustainable development of forest product industry in China needs circular economy. In this paper the basic concept of circular economy and the general situation of the development of modern forest product industry were introduced. The necessity of the development of circular economy and the realization of sustainable development of forest product industry were discussed. Suggestions were also put forward for the realization of circular economy in forest product industry.

\section{Author Contributions}

The Manuscript was written through contributions of all authors. All authors have given approval to the final version of the manuscript.

\section{Conflicts of Interest}

The authors declare that they have no competing interests. 


\section{Acknowledgements}

The research was supported by funding from Department of Forestry and Grassland Reform and Development, State Forestry and grassland administration (Project: "Study on circular economy of forestry industry").

\section{References}

[1] Ye K. L (2008) The practical dilemma and obligation approach of household garbage classification. China population, resources and environment, 29 (5): 118-126.

[2] Wang C. Y, Zhen X. X, Yu Q. T, Lei L (2019) The dilemma of green consumption: identity construction or environmental concern. Advances in Psychological Science, 27 (8): 1507-1520.

[3] Zhang M. M (2018) Thoughts on improving the current situation of waste classification in China. Journal of Green Science and Technology, 18: 111-113.

[4] Wang Z, Yang H, Wang D, Zhao Z (2019) Spatial distribution and growth association of regeneration in gaps of Chinese pine (Pinus tabuliformis Carr.) plantation in northern China. Forest Ecology Management, 432: 387-399.

[5] Wang Z, Yang H, Dong B, Zhou M, Ma L, Jia Z, Duan J (2017) Effects of canopy gap size on growth and spatial patterns of Chinese pine (Pinus tabulaeformis) regeneration. Forest Ecology Management, 385: 46-56.

[6] Dhyani V, Bhaskar T (2018) A comprehensive review on the pyrolysis of lignocellulosic biomass. Renewable Energy, 129: 695-716.
[7] Xiong M. Z, Bao F. C (2006) Study on the development superiority of modern wood industry in recycling economy. Wood Industry, 20 (1): 5-7.

[8] China Forest Products Industry Association, State Forestry Bureau Forest Industry Planning and Design Institute. China Wood Based Panel Industry Report 2019. 2019.

[9] Wang X. H (2007) Japan's Waste Classification Management Experience and Its Inspiration to China. Environmental Science and Management, 32 (9): 154-156.

[10] Li H. B, Lin Z. F (2019) Study on forestry industry ecology based on circular economy. Jiangxi Agriculture, 12: 88-89.

[11] Cui W. Z (2019) Study on the development of forestry industry from the perspective of circular economy. Science and Technology Innovation Herald, 16 (19): 255-257.

[12] Li Z. Q, Qi J. G, Wu G. S (2008) New Basic Principles of Modern Circular Economy: From 3R to 5R. The Journal of Quantitative \& Technical Economics, 25 (1): 53-59.

[13] Ji M, Geng L. M (2019) Study on the development of forestry biomass energy based on forestry circular economy. China Forestry Economy, 5: 12-14.

[14] Zhang Z. Z (2019) Theoretical Logic of the "Material Circulation and Reutilization" Thought: Based on the dimension of Marxist Green Development. Journal of Central South University of Forestry \& Technology (Social Sciences), 13 (1): 12-17.

[15] National Forestry and Grassland Administration. Code for Recycling Utilization of Waste Wood (LY/T1822-2019). Beijing: China Standards Press, 2019. 